\title{
Snap, Tweet and Post: College Student Social Media Perceptions and Heutagogic Practices and Uses
}

\author{
Louis S. Nadelson ${ }^{1}$, William Berg ${ }^{1}$, Brandon Fox ${ }^{1}$, Preston Grandbouche ${ }^{1}$, Michael Harris ${ }^{1}$, \\ Tia L. Kroschel ${ }^{1} \&$ Sean Sandoval ${ }^{1}$ \\ ${ }^{1}$ Colorado Mesa University, Grand Junction, CO 81501, USA \\ Correspondence: Louis Nadelson, Sponsored Programs and Academic Research, Colorado Mesa University, Grand \\ Junction, CO 81501 USA
}

Received: June 20, 2017

Accepted: July 10, 2017

Online Published: July 15, 2017

doi:10.5430/ijhe.v6n4p11

URL: https://doi.org/10.5430/ijhe.v6n4p11

\begin{abstract}
The nearly ubiquitous access to technology and the diversity of social media sites has provided students with easy access to a wide range of information and opportunities for interaction with other individuals. The nature of social media creates a context in which students can determine when they view information, the duration of the viewing, where they view their social media and why they choose to view the media. The conditions of social media interactions present an opportunity for self-determined learning, or heutagogy. While heutagogy takes place multiple time during a student's average day, the self-determined nature of the learning may lead to issues associated with challenges to self-regulation and anti-social behaviors. To study student self-determined perceptions and engagement with social media we developed a mixed methods survey gathering quantitative and qualitative data from 71 undergraduate students. Our results reveal students do self-determine multiple aspect of their engagement with social media including the norms they use for engagement. We also found that the students perceived that they gave up other activities to engage in social media, and were likely to spend more time studying, exercising, and bettering themselves of they did not spend time interacting with social media.
\end{abstract}

Keywords: Heutagogy, Social media, Self-determined learning, Risky behaviors

\section{Introduction}

Walk across a typical college campus in the United States and you will likely view the majority of students looking at their smart phones as they move about. Informal conversations with the students looking at their phones revealed most were viewing some sort of social media. The high level of intrinsically motivated engagement with social media provided us with an interesting context for exploring the choices students make when engaging in self-directed activities. The nearly constant interaction with social media by many students led us to wonder; what are they viewing and why, what are their practices and behaviors associated with viewing social media, why are they engaging with social media, and what might they be doing if they were not occupied with social media.

In our review of the research, we found several reports detailing studies of conditions in which students were expected to use social media for formal learning experiences (e.g. Dabbagh \& Kitsantas, 2012). The studies tend to focus on special uses of a specific social media or a unique context that involved social media interaction while only eluding to or superficially researching the students' perceptions of the norms for using social media and the perceptions and justification for social media engagement. We were not able to locate any studies that explicitly and especially examined students' perceptions, practices, and uses of social media independent of a specific context or platform: conditions reflective of social media interactions that are guided by students' self-determined preferences and goals. Further, we were not able to find any reports that took into consideration the self-determined nature of social media interaction when studying student practices and norms of engagement with social media. Our research addressed these gaps in the literature by surveying college students with regard to their social media use and behaviors through the lens of self-determined learning or heutagogy. With the rapid developments in and evolution of technology and widespread access to social media, there is justification for continuing to empirically document the associated student uses, perceptions and practices. 


\section{Review of Literature}

\subsection{Heutagogy and Social Media Engagement}

Social media has become ubiquitous and an integral part of our society, including the college campus experience. Pempek, et al. (2009) reported that $91 \%$ of college students across multiple large universities in the United States, Midwest region, regularly used Facebook.com. The complexity of student informal use of social media may be most effectively characterized by considering their engagement through a lens of "heutagogy" or self-determined learning (Blaschke, 2012, 2014; Nadelson et al., 2016). Social media may be embedded as part of the instructional processes and curricular content of a course in ways that engage students in learning is directed (i.e. specific assignments given that require social media use in specific ways) or self-directed (Tess, 2013). However, the vast majority of students' engagement in social media is self-determined and involves informal learning with the students choosing what to view, the duration of the viewing, the frequency in which they view content, and their response to the content (Blaschke, 2012, 2014; Nadelson et al., 2016). The self-determined nature of engagement with social media suggests that students are intrinsically motivated as they determine the content they view, the duration of their engagement, how they use the media, and how they respond to the information they view (Ryan \& Deci, 2000). Because students can self-determine their engagement with social media content and the platform use for engagement they are also likely to self-determine the acceptable norms and practices for social media participation (Bolton et al., 2013; Deci \& Ryan, 2000). We determined that examining engagement with social media through the lens of heutagogy (Hase \& Kenyon, 2000) created an opportunity to effectively document and explain students' self-determined practices, perceptions and uses of social media.

\subsection{Potential Academic Benefits of Student Engagement in Social Media}

There are several potential benefits to using social media in college settings that catalyze student participation in social media, institutional events, and course related activities (Blaschke, 2012, 2014). For example, students may configure their social media accounts to stream campus news and announcements to be notified about campus and community events and developments (Achen, 2015; Junco, 2012). Configuring their social media to stream information about campus activities is likely to increase student awareness of opportunities that lead to increases in student engagement, participation and a sense of belonging to the institution (Gray, Vitak, Easton, \& Ellison, 2013). Thus, students who use social media to keep informed about campus and community events and opportunities may be more engaged and committed to the institution and associated community, which is likely to be perceived as a positive academic outcome for the use of social media.

Social media has had a profound impact on the way we communicate, obtain information and share media (e.g., Isaacs, 2014). As the use of social media for communication continues to grow in popularity and becomes a societal norm, there are high expectations for the functionality, ease of access, and capacity of social media software (Quan-Haase \& Young, 2010). For example, Gikas and Grant (2013) found that college students across three universities tended to use mobile computing devices to engage with social media in ways that lead to increased opportunities for student interaction, opportunities for collaboration, and conditions that permitted the students to contribute to social media content creation and communication. Consequently, more university teachers are embracing the idea that social media can be used as an instructional tool to expand opportunities for teaching and learning (Grosseck, Bran \& Tiru, 2011). Despite the high popularity of social media use, there is a relatively low percentage of students and instructors using the media to engage in enhance their formal educational interactions (Chen \& Bryer, 2012). The high potential for benefit and the relatively low use led use to wonder how college students are using social media, and is the outcome of the use beneficial to their studies, engagement with the campus, and activities in the community.

Social media has been found to be a useful tool for college students to communicate with their peers and teachers (Pempek, Yermolayeva, \& Calvert, 2009). Students can use social media to work on assignments and communicate with other students to collaborate on learning or seek and receive academic support. Thus, given the potential benefits to learning and being informed of campus and community events, we determined that we had warrant to determine the extent to which students are choosing to use social media to support their academic achievement and engagement.

\subsection{Potential Detriments of Social Media to College Students}

Although there are many potential personal and societal benefits for the use of social media, there are also claims that social media use can have a negative impact on student social and academic engagement. Kandell (2009) reports that college students who use social media frequently may be susceptible to pathological internet use. Given the 
self-determined nature of social media engagement, there is potential that many students may not have the self-regulation capacity to effectively regulate the frequency, timing or duration of engagement (Wegmann, Stodt, \& Brand, 2015). As Kittenger, Correia and Irons (2006) conclude that a substantial number of students were found to experience problems with Internet use, and social media seemed to exacerbate the symptoms related to addictive Internet usage. Further, the self-determined nature of social media allows students to view content unrelated to their academic studies or environment, making the media a distraction. Consequently, college students who may be at high risk for low academic achievement may experience even greater probability of failure with unregulated access to social media. Thus, there is justification for examining college student perceptions, practices, and uses of social media as their behaviors and reasoning for their social media use may provide insight into their heutagogy driven Internet engagement which is commonly associated with their academic performance.

Aside from the potential impact of internet addiction on student academic performance, there is potential that their uses and perceptions of social media is detrimental to their learning. Jacobsen and Forste (2011) report a potential inverse relationship between student engagement with electronic media and their academic performance. Jacobsen and Forste found that social media often presents students with distractions that interfere with time devoted to doing homework by reducing student focus on homework tasks and content, which reduces academic success. The distraction appears to be widespread through students' academic experiences as Jacobsen and Forste report that more than half of college students use electronic media when doing homework or while in class. The attention toward multiple activities requires students to multitask which has been documented to be extremely rare if not impossible (Burak, 2012). Therefore, being distracted by social media is potentially disruptive to academic focus and may be associated with lack of attention toward learning, lower academic performance, and increases in other risk behaviors (Burak, 2012). Karpinski (2012) reports that college students who are active on large member social media networks tend to have lower academic performance compared to their peers who do not engage in the networks. Determining student usage and perceptions of social media with respect to being a distraction may provide insight into the extent to which they may be distracted from an academic focus and likely to use social media as a justification for engaging in socially appropriate behaviors and activities.

Given the potential for social media to influence students' academic achievement and propensity to build social capital, there is justification for continuing to monitor students' perceptions, uses, and self-determined practices with social media. Given the possibility that social media may negatively impact college student's success on campus, as well as increases the student's likelihood of becoming addicted to the Internet, it is important we continue to investigate how, why and when students self-determinedly engage with social media.

\subsection{Social Media Limiting Opportunities}

There is an interesting association between openness to new experiences and social media use, as Correa, et al. (2010) reports people who yearned for new experiences engaged with social media more frequently than their peers who seek higher levels of consistency. Thus, those who frequently use social media are likely to be open to other novel experiences but, paradoxically they may not engage in the experiences due to their time being devoted to social media interaction. College students across the country immerse themselves in an array of social media, allocating substantial time in their social media engagement (Ellison, 2007). With an average of about six hours per day spent interacting and monitoring social media sites (Roberts, et al., 2005), it does raise the question as to what activities students are giving up or are not attending to as a result of interacting with social media. Thus, there is justification for examining how much time students spend using social media, what they would do if they were not engaging with social media, and do they feel that they give up opportunities to engage in other activities due to their social media use.

While many new social media applications have become widely available, Facebook is still the leading platform for social media use (Assnani, 2014). Valenzuela, (2009) reports that college students' Facebook use was positively correlated with their general life satisfaction, social trust, civic engagement, and political participation. However, while there are some potential benefits to using social media (Valenzuela, 2009) engagement in social media may lead to increased levels of envy and jealousy and in some cases depression (Tandoc, 2015). Further, some students spend upwards of eight hours every day on Facebook and other social media sites; which Vishwanath, (2014) contends could lead to the development of cognitive and behavioral disorders. The time students spend on social media may be at the expense of other activities such as engaging in academic studies and coursework which is likely to negatively impact overall academic performance and personal well-being (Juncol, 2015). Therefore, there is justification for examining students' social media perceptions, uses, and practices, particularly to determine if students may be using social media at the expense of other activities. 


\section{Method}

Our overarching research question was, "In their self-determine engagement with social media, what are students' perceptions, practices, and uses of social media?" To guide our research and answer our research question we developed the following guiding questions:

- How do students define social media?

- What do students perceive to be the impact of using social media?

- What are students' choices for social media and what are they doing with the media?

- What are students' perceptions of social media and what would they do if they did not have access to social media?

\subsection{Participants}

The participants in our research were the students enrolled in a regional public university in the Rocky Mountain west of the United States who voluntarily completed our survey. We recruited undergraduate students to participate in our survey by emailing several cooperating professors our recruiting email and asked the professors to post the invitation on their course management sites. We had 77 students enter the survey but only 71 completed all items. Of the 71 who completed the survey, approximately $60 \%$ were female and $40 \%$ male. Approximately $71 \%$ were Caucasian, $10 \%$ identified as Hispanic, 5\% indicated mixed ethnicity, and the remaining 14\% were nearly equally distributed among four other ethnic groups. The participants were on average 20.57 years old $(S D=3.13)$ and attended an average of 2.32 years of college $(S D=1.48)$. The participants were distributed among a variety of degree programs as shown in Figure 1.

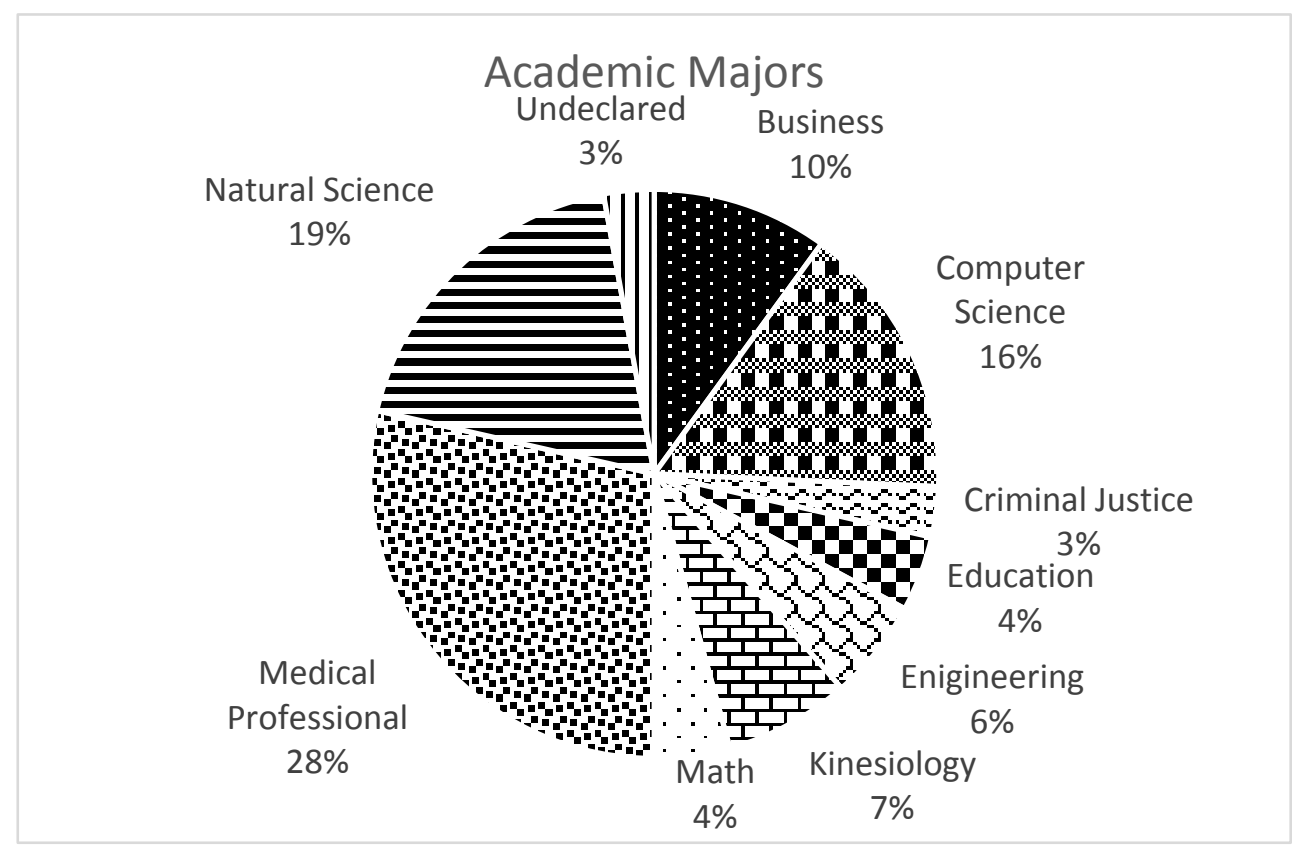

Figure 1. Percentage of participants in degree programs

On a 10-point political orientation scale ranging from 1 being "Conservative" to 10 being "Liberal" the students were on average $4.6(S D=2.43)$ which we interpreted to be slightly more conservative than liberal. On a similar 10-point scale with 1 being "Introvert" and 10 being "Extrovert" the students indicated that they were an average of 5.54 (SD $=2.01$ ) which suggests that the students were slightly more extroverted than introverted. On a 10-point technology competency scale ranging from 1 being "Need a lot of help" and 10 being "Expert" the students averaged $7.50(S D=$ 1.91) suggesting that the students were approaching expert in terms of their competency. The students had an average of 3.36 internet connected devices $(S D=1.71)$ and used an average of 2.4 of those regularly $(S D=.91)$.

\subsection{Survey Tool}

We were unable to locate an extant tool to gather the data necessary to answer our research questions. Therefore, using an iterative process we developed a survey tool that consisted of general demographic items and an array of 
items related to students' perceptions of social media and their associated self-determined uses and practices. Given the exploratory nature of our research, that is social media use through the lens of heutagogy, we determined that we could keep the items rather simple and establish the validity through group discussion and piloting the tool with undergraduate students. Further, we determined our development was necessary due to the desire to answer social media use, practices, and perceptions questions that were unrelated to academic programs and focus, which is a theme common to many surveys of college student social media use.

Through our discussions, we determined we needed to use a combination of selected response and free response items to gather the data we were seeking. Thus, we created rank order items to gather data regarding students' perceptions regarding appropriate times to use social media such as "when driving" "while on a date" and "in class." We followed the item with a free-response question which asked the students to describe a time they were inappropriately using social media. To determine how students justified the norms for their use of social media we asked questions such as, "Do you check your social media when you wake up at night?" and "Do you check your social media when you are driving?" which the students answered using a Likert-like scale ranging from " 1 " which represented "Never" to "5" which represented "Constantly".

Through several rounds of discussion and revisions, we refined our survey assuring that the items were aligned with our guiding research questions. Further, we shortened the survey to avoid participant fatigue and reduce our incomplete response rate. We vetted our survey with several undergraduate students and asked for their feedback about the items and general survey format. Based on their comments we determined that we had sufficient construct and content validity and could progress with our research using the refined instruments. The final survey contained 29 items, which can preview at: https://www.surveymonkey.com/r/Preview/?sm=b3 2Fe9L_pdmiNbS6wbmglBIVy_2BhYtgEbAHplBWAsYXV_2Fl ryvyINZlcxYMYz0eZzIPF

\subsection{Data Collection}

All data collection took place online using a web based survey tool. Students were notified of the survey by their professors who posted the research opportunity to their course management system. We did not offer any incentives to the students and all participation was voluntary. We collected data for three weeks during the middle of an academic semester. The research was conducted with Institutional Review Board approval and human subject oversight.

\section{Results}

\subsection{Defining Social Media}

Our first research question asked, "How do students define social media?" To answer this question we examined the responses to our items which asked students to define social media and to determine if certain forms of communication were considered to be social media. We began our analysis by examining the outcome of our related selected response items. Our analysis of our Likert-scale item asking if the participants considered social media to be any media that connects people revealed about $47.1 \%$ responding "Strongly Disagree" "Disagree" or "Neutral" and $52.9 \%$ responding with "Agree" or "Strongly Agree" which suggests about half of the students did not consider social media to be media that allows people to connect. Our analysis of participants' responses to our item asking if they considered "texting" to be social media revealed 77.2\% selecting "Not at all" "A little bit" or "Somewhat" with only 5.7\% selecting "Completely" which suggests that the majority of students do not consider texting to be a form of social media. Our analysis of the responses to our Likert-scale item asking if video conferencing applications are not social media revealed $75.0 \%$ responding "Strongly Disagree" "Disagree" or "Neutral" and only 6.3\% responding "Strongly Agree" which indicates that most students would consider video conferencing to be social media.

We continued our analysis by examining and coding the responses to our free-response items related to defining social media. We coded our item asking the students to define social media by examining the responses for indicators of the elements or practices associated with social media. Thus, we coded for references to "technology" ,"connecting with others" "'networking", "multiple media forms", "community", and "sharing." To establish interrater reliability, we coded a small set of the responses independently and then compared our results, discussing differences in coding until we reached agreement. We repeated this process until we had $90 \%$ consistency in coding at which time we coded the remaining responses individually. We present the results of our coding in Table 1 . We found that about $71 \%$ of the participants conveyed some knowledge to no knowledge in their definitions of social media. We coded about $3.4 \%$ of the responses as comprehensive definitions, which suggests students who may be using social media still struggle to define social media. 
Table 1. Coded responses of definitions of social media

\begin{tabular}{|c|c|c|}
\hline Score - Knowledge Level & Percentage & Representative Response \\
\hline 0 - No knowledge or No response & $3.4 \%$ & Looking at a device for attention. \\
\hline 1 - Limited knowledge & $22.0 \%$ & Facebook, etc. \\
\hline 2 - Some knowledge & $45.7 \%$ & A platform to connect with people. \\
\hline 3 - Working knowledge & $25.4 \%$ & $\begin{array}{l}\text { A tool people use to stay connected with one } \\
\text { another. }\end{array}$ \\
\hline 4 - Comprehensive knowledge & $3.4 \%$ & $\begin{array}{l}\text { A platform which people can communicate and } \\
\text { share with each other on the internet, usually } \\
\text { posting pictures or memes. }\end{array}$ \\
\hline
\end{tabular}

We took a similar approach to the coding of the explanations students provided to our item asking them to share why they would or would not consider texting to be a form of social media (See Table 2). We found that those who did not consider texting to be social media made the division due to the potentially private manner in which texting occurs. In contrast, those who did agree that texting was a form of social media recognized the social interaction that takes place using technology.

Table 2. Explanations of perceptions of texting as social media

\begin{tabular}{lll}
\hline Score & Percentage & Representative Response \\
\hline 1- Not at all & $31.3 \%$ & $\begin{array}{l}\text { Texting is like writing a letter it's between you and one other person. It } \\
\text { maintains privacy and personal boundaries that social media can sometimes } \\
\text { cross. }\end{array}$ \\
2- A little bit & $26.6 \%$ & $\begin{array}{l}\text { In a way, texting is kind of like keeping just the recipients of whom you're } \\
\text { texting, updated on your life and vice versa. }\end{array}$ \\
3 - Somewhat & $26.6 \%$ & $\begin{array}{l}\text { Texting still allows you to communicate with people and express yourself } \\
\text { but is only between a person or a group directly. }\end{array}$ \\
4 - A lot & $9.4 \%$ & $\begin{array}{l}\text { I would most definitely consider texting a social media because it follows the } \\
\text { description of what social media is. It allows individuals to express their } \\
\text { feelings, interests, and can also include topics on today's society. }\end{array}$ \\
5 - Completely & $6.3 \%$ & $\begin{array}{l}\text { It fits my definition, texting is interacting socially with others through a } \\
\text { digital interface. }\end{array}$ \\
\hline
\end{tabular}

\subsection{Perceived Impact of Social Media}

Our second research question asked, "What do students perceive to be the impact of using social media?" To answer this question, we examined our participants responses to our items that asked students to share their perceptions of the impact of social media. We began by examining the items for correlations and found several relationships (see Table 3). The perception that social media has had a negative impact on a friendship or relationship was found to be statistically significantly associated with giving up other activities to engage in social media $(r=.26, p<.05)$, social media being time consuming $(r=.41, p<.01)$, use of social media encouraged by others $(r=.29, p<.05)$, checking social media at night when woken up $(r=.27, p<.05)$, and checking while driving $(r=.29, p<.05)$. Thus, our data suggest that there appears be a relationship between the experience of social media having a negative effect on a relationship and willingness to engage in a number of risky or anti-social behaviors due to social media use. 
Table 3. Correlations of impact of social media

\begin{tabular}{|c|c|c|c|c|c|c|c|}
\hline & $\begin{array}{l}\text { I have to } \\
\text { give up } \\
\text { other } \\
\text { activities } \\
\text { to } \\
\text { participate } \\
\text { in social } \\
\text { media. }\end{array}$ & $\begin{array}{l}\text { If social } \\
\text { media was } \\
\text { nonexistent } \\
\text { I would } \\
\text { have extra } \\
\text { time in my } \\
\text { day. }\end{array}$ & $\begin{array}{l}\text { I am } \\
\text { encouraged } \\
\text { by others to } \\
\text { use social } \\
\text { media. }\end{array}$ & $\begin{array}{l}\text { Social } \\
\text { media has } \\
\text { a positive } \\
\text { impact on } \\
\text { society as } \\
\text { a whole. }\end{array}$ & $\begin{array}{l}\text { I check } \\
\text { my } \\
\text { social } \\
\text { media } \\
\text { when I } \\
\text { wake up } \\
\text { at night }\end{array}$ & $\begin{array}{l}\text { I am } \\
\text { willing } \\
\text { to stop a } \\
\text { conversati } \\
\text { on to } \\
\text { check my } \\
\text { social } \\
\text { media. }\end{array}$ & $\begin{array}{l}\text { I check } \\
\text { my } \\
\text { social } \\
\text { media } \\
\text { while } \\
\text { driving } \\
\text {. }\end{array}$ \\
\hline $\begin{array}{l}\text { Has had a negative } \\
\text { effect on a } \\
\text { friendship/relationship }\end{array}$ & $.26^{*}$ & $.41^{* * *}$ & $.29^{*}$ & -.14 & $.27^{*}$ & .14 & $.29^{*}$ \\
\hline $\begin{array}{l}\text { I have to give up other } \\
\text { activities to participate } \\
\text { in social media. }\end{array}$ & & $.42^{* *}$ & $.26^{*}$ & .09 & .14 & .01 & .10 \\
\hline $\begin{array}{l}\text { If social media was } \\
\text { nonexistent I would } \\
\text { have extra time in my } \\
\text { day. }\end{array}$ & & & $.27^{*}$ & -.06 & .20 & .04 & .05 \\
\hline $\begin{array}{l}\text { I am encouraged by } \\
\text { others to use social } \\
\text { media. }\end{array}$ & & & & .14 & .12 & -.03 & .10 \\
\hline $\begin{array}{l}\text { Social media has a } \\
\text { positive impact on } \\
\text { society as a whole. }\end{array}$ & & & & & -.13 & -.12 & -.11 \\
\hline $\begin{array}{l}\text { I check my social } \\
\text { media when I wake up } \\
\text { at night }\end{array}$ & & & & & & .12 & .19 \\
\hline $\begin{array}{l}\text { I am willing to stop a } \\
\text { conversation to check } \\
\text { my social media. }\end{array}$ & & & & & & & .03 \\
\hline
\end{tabular}

We also found a relationship between desire to use social media rather than socialize in person and the willingness to stop a conversation to check social media $(r=.26, p=.038)$. Our analysis revealed that those who indicated that social media is a priority perceived that they would have more time in their day without social media $(r=.34, p<.01)$ and that they are more likely to be encouraged to use social media by their peers $(r=.38, p<.01)$.

We continued our analysis with a series of t-tests using the value of 3 (representing a neutral response on a five-point Likert scale) as the test value. We found that the students' average response to our item asking them about social media's impact on society as a whole to be $2.62(\mathrm{SD}=.98)$ which is significantly less than neutral $(t=-3.05, p<.01)$, indicating that the students perceive social media to be having a more negative than positive impact on society. Our analysis of the response to the item regarding social media having a negative effect on relationships revealed an average of $2.41(\mathrm{SD}=1.07)$ to be significantly less than neutral $(t=-4.46, p<.01)$, indicating that the students tended to perceive that social media has not negatively impacting their relationships.

In our analysis of what students did not like about social media we found the greatest response for "time consuming" and "distracting" (31\%). Drama and negativity (14.3\%), distancing from personal interactions (15.7\%), and the "other" category (12.9\%) were nearly equally mentioned as reasons for not liking social media (see Figure 2). The "other" category included responses related to issues of politics, advertising, and the superficial nature of social media connections. A smaller number of participants responded that they did not like the lack of privacy (5.7\%). A rather small percentage of participants indicated that they did not have a least favorite factor associated with social media (4.3\%). 


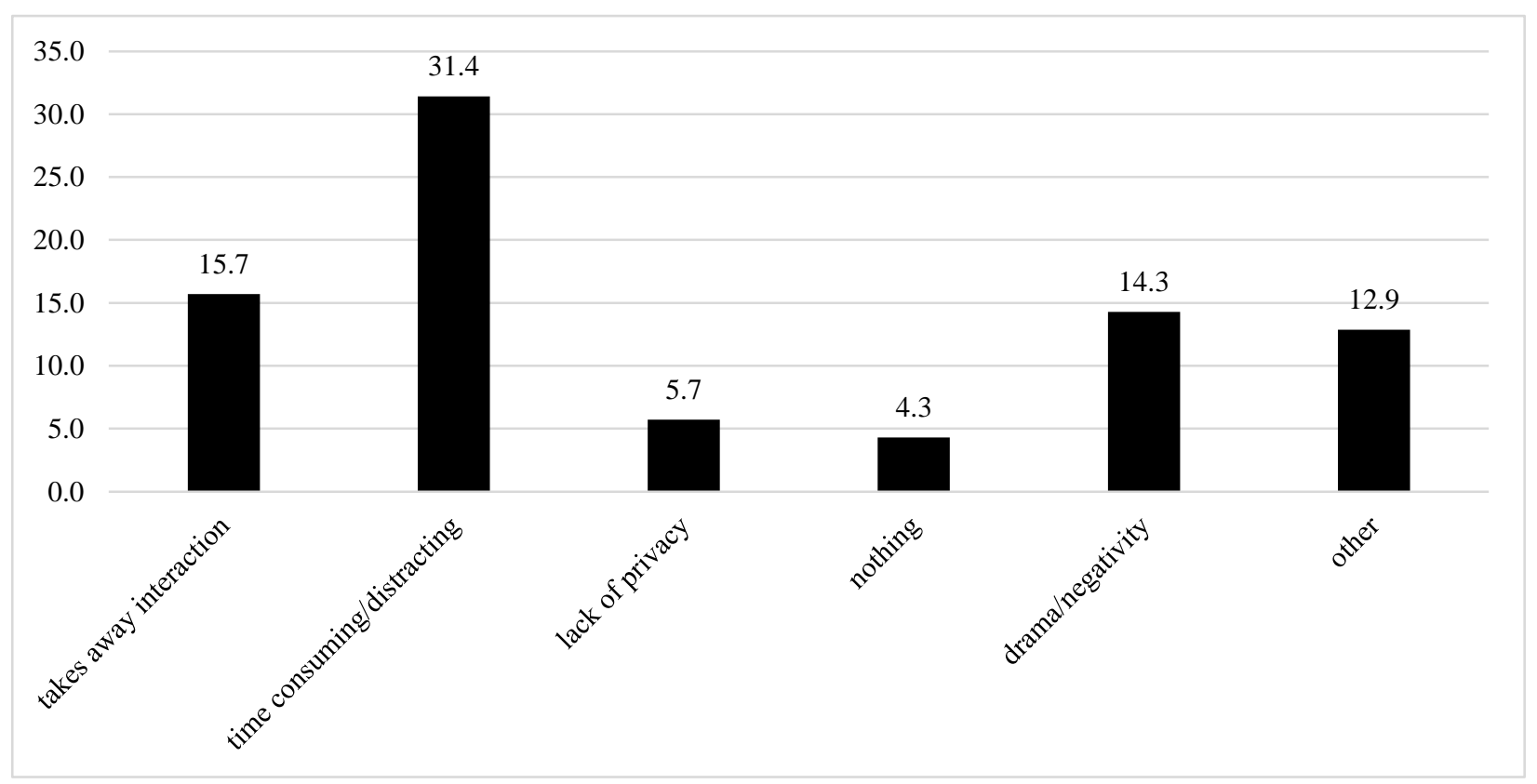

Figure 2. Least favorite aspect of social media

\subsection{Students' Uses of Social Media}

Our third research question asked, "What are students choices for social media and what are they doing with the media?" To answer this question, we examined the participants' responses to our items that asked students to share how they used social media and when they thought it was appropriate to use the media. We first examined the social media platform that students used as a potential indicator for how they may be using social media. We found that students tended to use Facebook, Snapchat, and Instagram most frequently, Twitter and Pinterest occasionally, and Parascope and Tumblr seldom (see Figure 3).

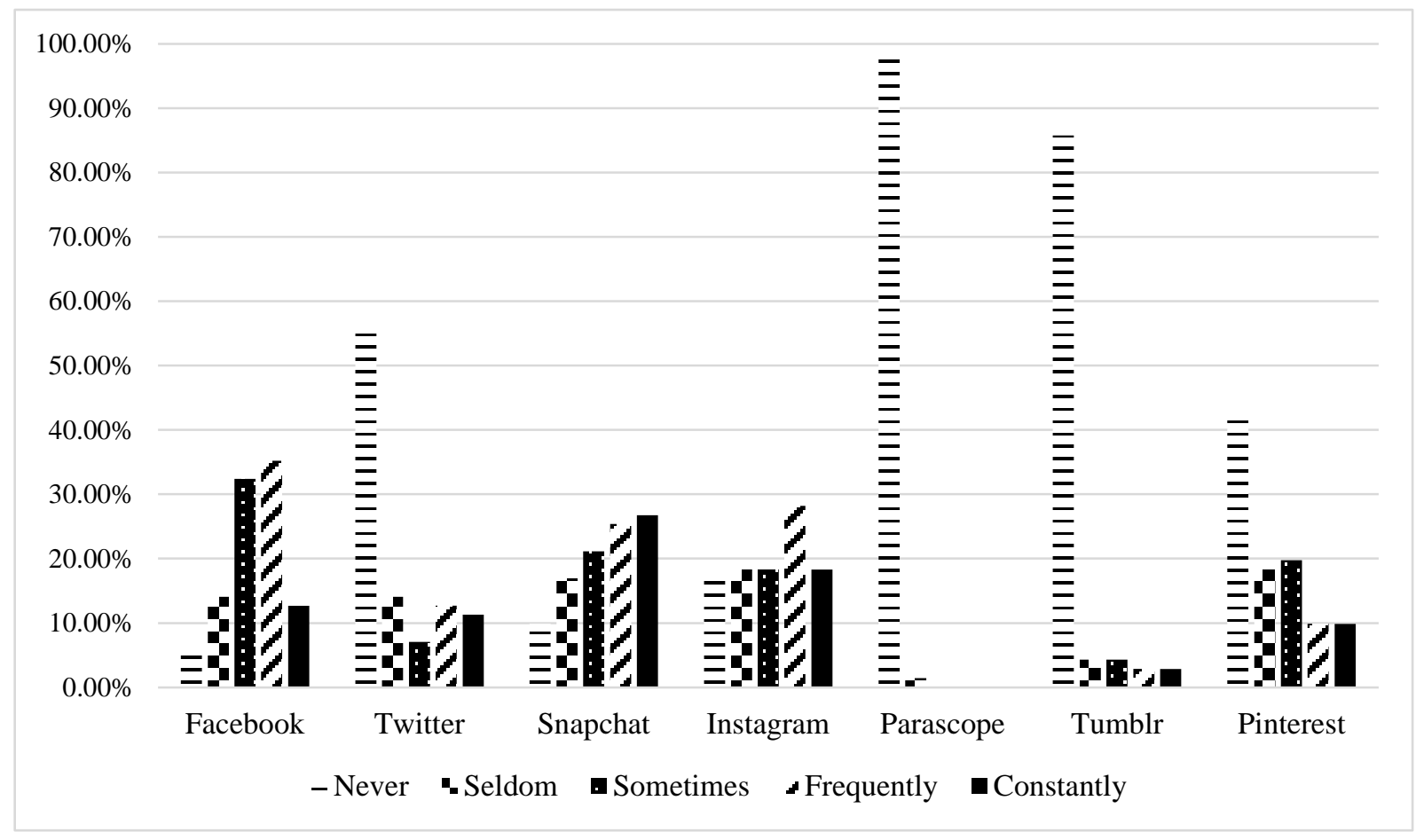

Figure 3. The social media platforms student used 
In our analysis of when students thought it was acceptable to use social media we found high levels of unacceptable perceptions when driving, on a date, and while riding a bike, yet some students indicated some or moderate use in these situations. The students tended to perceive it was moderately unacceptable to check social media while at dinner and in class, with moderate acceptance indicated my many. The students in general indicated it was acceptable to use social media while walking. Both being a passenger in car and while alone were rated as highly acceptable for extensive use of social media (see Figure 4).

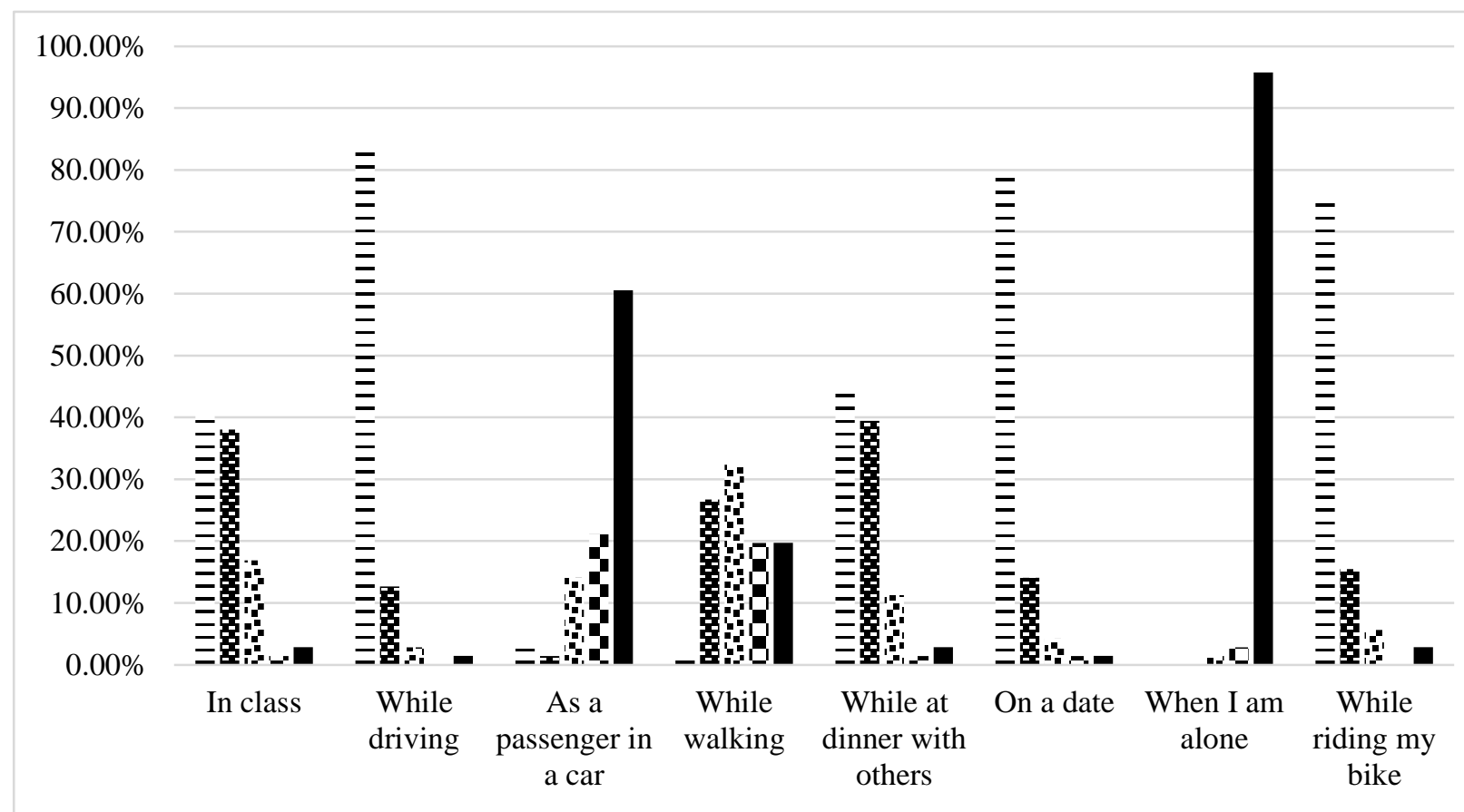

= Never Ok to take a quick peek $\mathbf{\sigma}$ Ok for a few moments $\sqcup$ Ok to get up-dates $\square$ Ok to as much an I want

Figure 4. Students perceptions of when it is acceptable to view their social media

We asked our participants how much they used social media each day and how frequently they checked their media daily. For both questions, (answered in a five-point Likert-like scale) there were no responses for "zero" or "none" (see Figures 5 and 6). The average for daily social media use was about 2.5 hours. The average frequency was between once and twice an hour. These indicate that the students spend a fair amount of the day engaging in social media with relatively frequent interactions. 


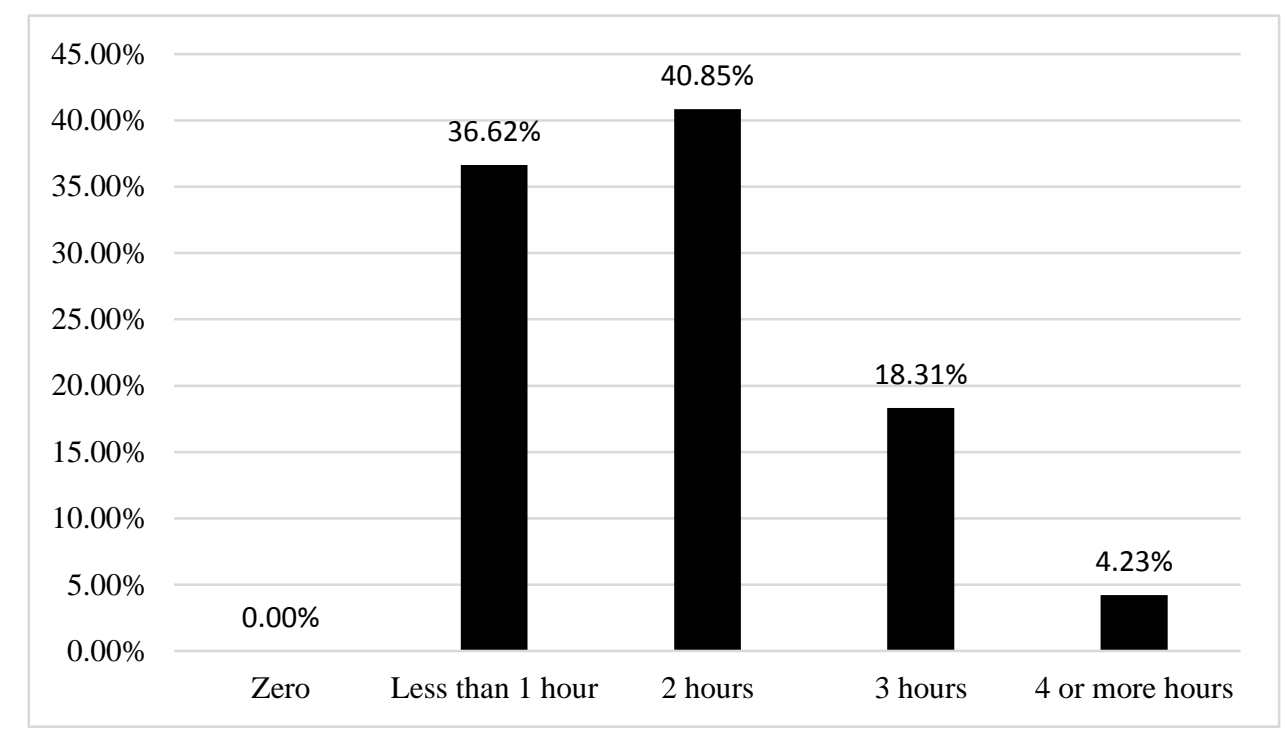

Figure 5. The participants' daily use of social media

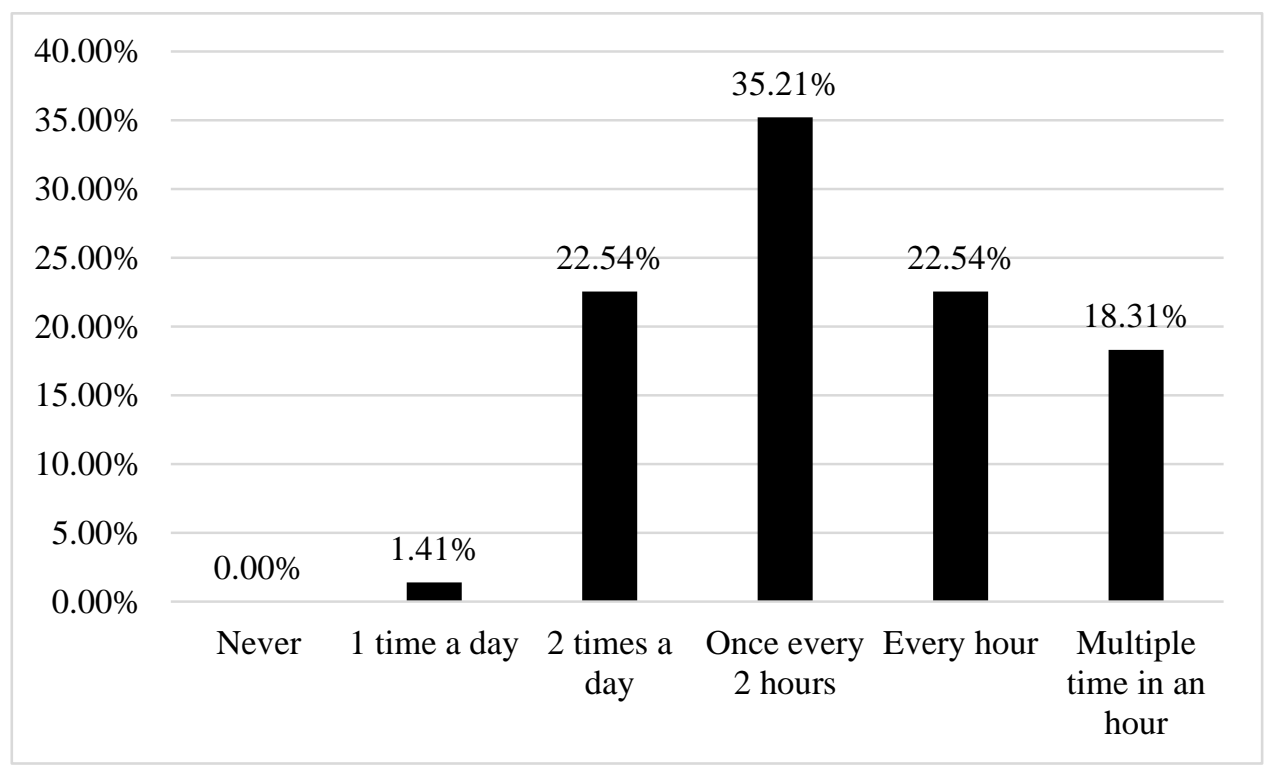

Figure 6. Frequency with which the participants checked their social media daily

Our analysis of the students' responses to their perceptions of the purpose of social media and how they typically used social media revealed a high percentage indicating that they used social media to connect with others. Substantially, a fewer percentage of students indicated other uses of social media, however, filling time, entertainment, staying informed, and sharing thoughts with others were ranked nearly evenly at about $10 \%$ of the responses regarding the primary purpose the students used social media (see Figure 7). 


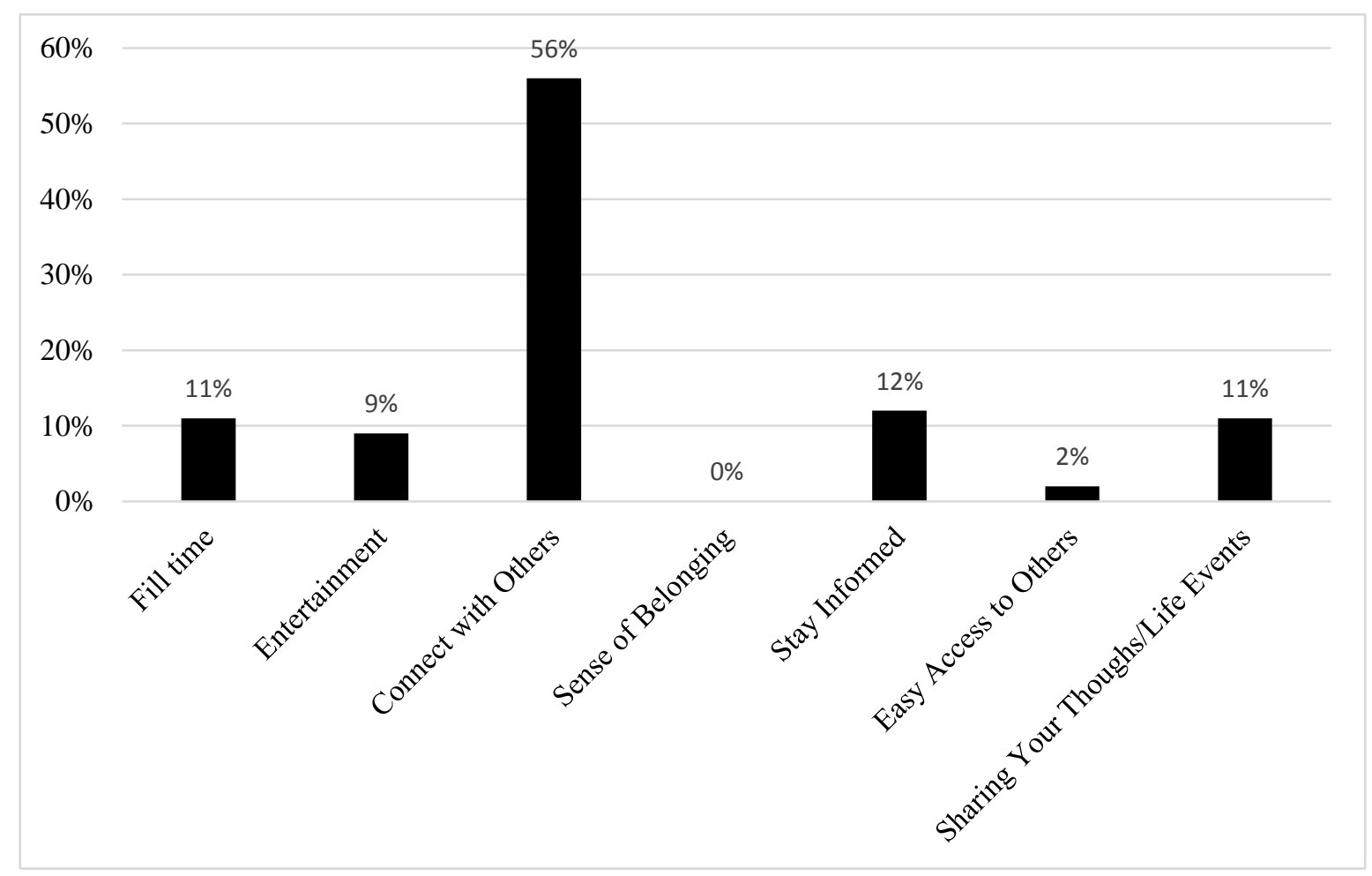

Figure 7. The students main reason for using social media

To determine the nature of the information students seek when they interact with social media we examined their responses to our item asking them to select their primary use of social media. Our analysis revealed no response to playing games or taking quizzes, $4.23 \%$ used social media to monitor sports events and teams, $7.04 \%$ used social media to find events, $18.31 \%$ responded that they used social media for newsfeeds, $28.17 \%$ indicated that they used social media for viewing photos, and the most frequently selected primary use of social media was status reports from friends and family (See Figure 8).

Status updates (content from friends)

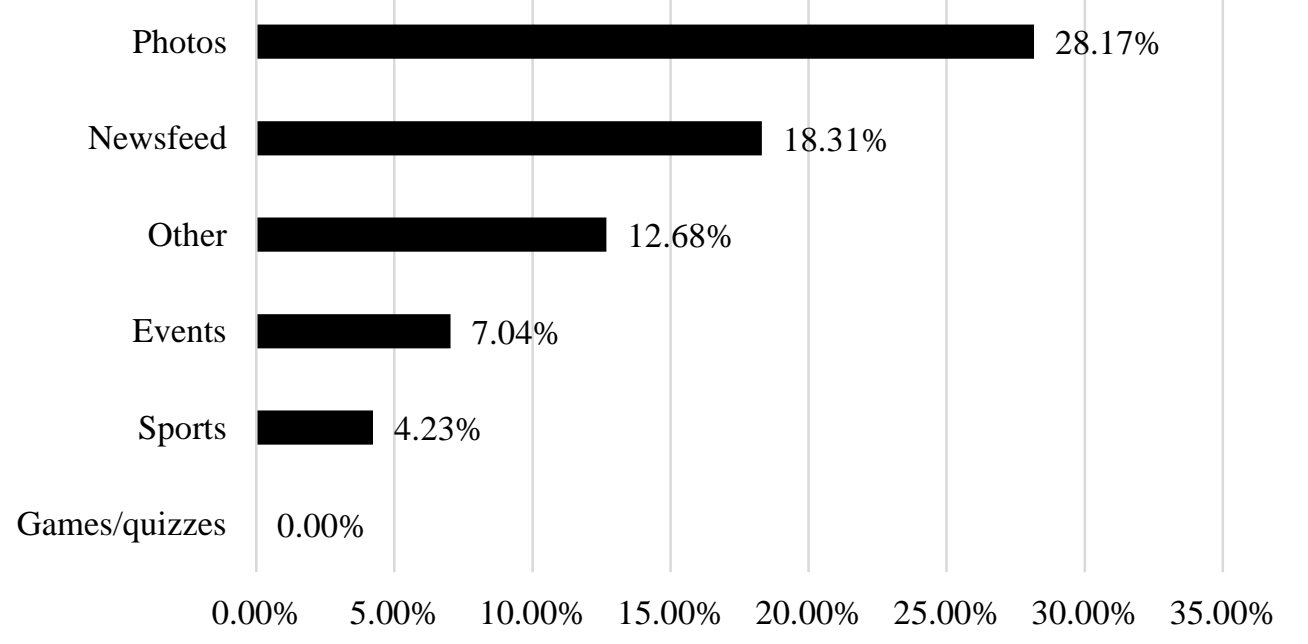

Figure 8. Student response to the information they seek when viewing social media 


\subsection{Perception and Alternatives to Social Media}

Our final research question asked, "What are students perceptions of social media and what would they do if they did not have access to social media?" To answer this question, we examined the students' responses to our items related to alternatives to social media and their perceptions of social media being a distraction. We began our analysis by examining the responses to our item asking the students if they give up other activities when engaging in social media (see Figure 9). We found that about three quarters of the participants disagreed with the notion that using social media took them away from participating in other activities. In contrast, over half of the participants agreed that they would have "more time in their day" if there was no social media (see Figure 9).

We found a significant correlation between the participants' perception that they give up other activities to engage in social media and their perception that they would have extra time in their day if social media was non-existent (Spearman's Rho $=.44, p<.00$ ). Our results suggest that those students who give up activities to engage in social media would likely engage in those activities if social media did not exist.

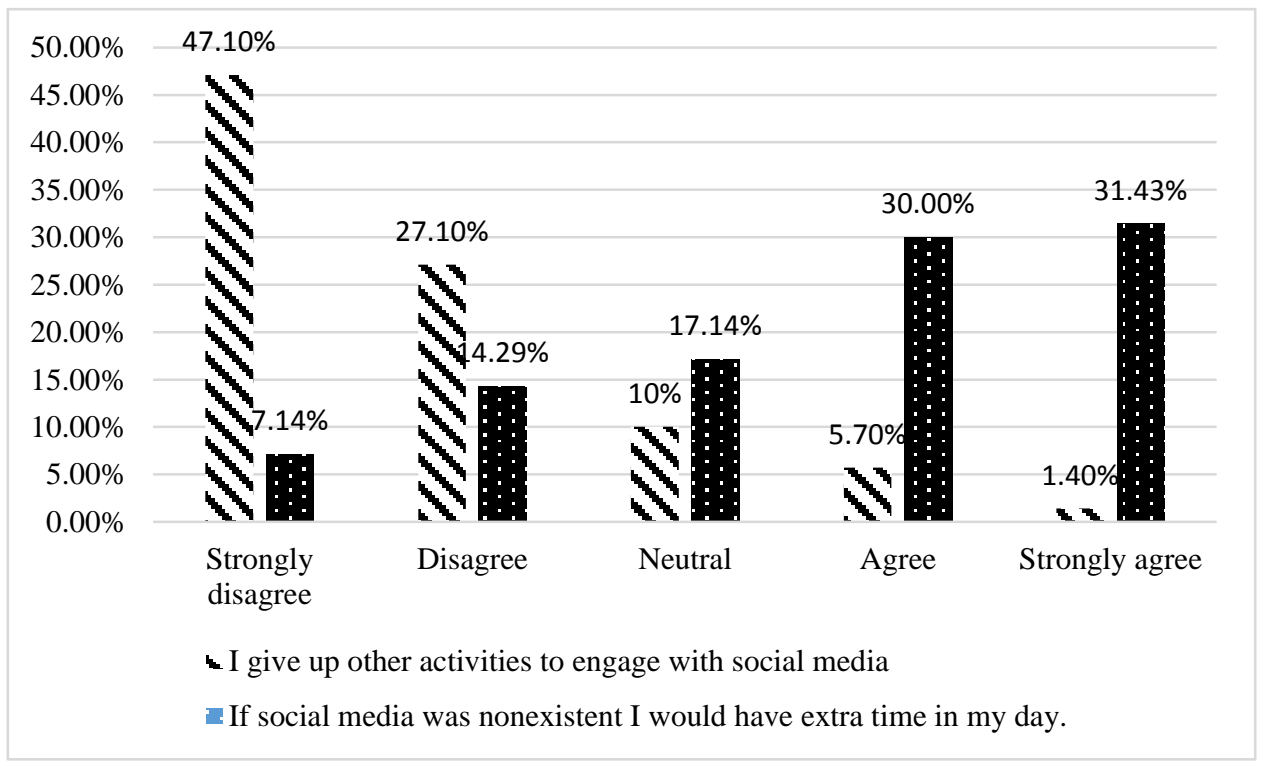

Figure 9. Percentage of students' responses to the item asking them if they have to give up other activities to participate in social media

In our survey we asked the participants to share a time when they were using social media when they feel they should not have been. All of our participants provided responses to this item. Nearly all of the responses included some sort of justification for the inappropriate use such as, "A wedding. The ceremony was boring me." and "During a particularly boring dinner with my parents." and "Checked my phone at work a few times when I had nothing to do." and, finally, "I was talking to my dad on the phone while scrolling through social media." Some of the responses indicated some level of shame for the inappropriate interactions with social media such as, "Driving. I hate that I am so interested in social media that it distracts me while driving." and "I've read twitter while people around me have described dark personal stuff and that's probably inappropriate." and "During a really remedial lecture that was extremely boring. I know it was rude, but still did it." and finally, "During church... But.. It WAS church." Thus, it appears that while students may be developing their own norms for social media use, they are likely to recognize their use of social media at different times to be inappropriate, and therefore may feel a need to justify their actions or indicate some level of regret.

To find out what the students were likely to be doing if they were not engaged in social media we analyzed their responses to our selected response item asking them how likely they were to engage in a range of activities. The five-point scale ranged from "Never" (1) to "Extremely Likely" (5). We averaged the responses to determine overall trends (see Figure 10). The average of the responses to engaging with other technology instead of using social media was the lowest rated activity $(M=3.37, S D=1.16)$. The responses to the other alternative activities that were not necessarily technology related such as physical activity, school or work, and outside activities were centered around likely with averages ranging from 3.68 to 4.03 ( $S D$ ranging from .94 to 1.10). Thus, our results suggest that while the students might consider interacting with other technology in place of social media they would be more likely to participate in non-technology activities. 


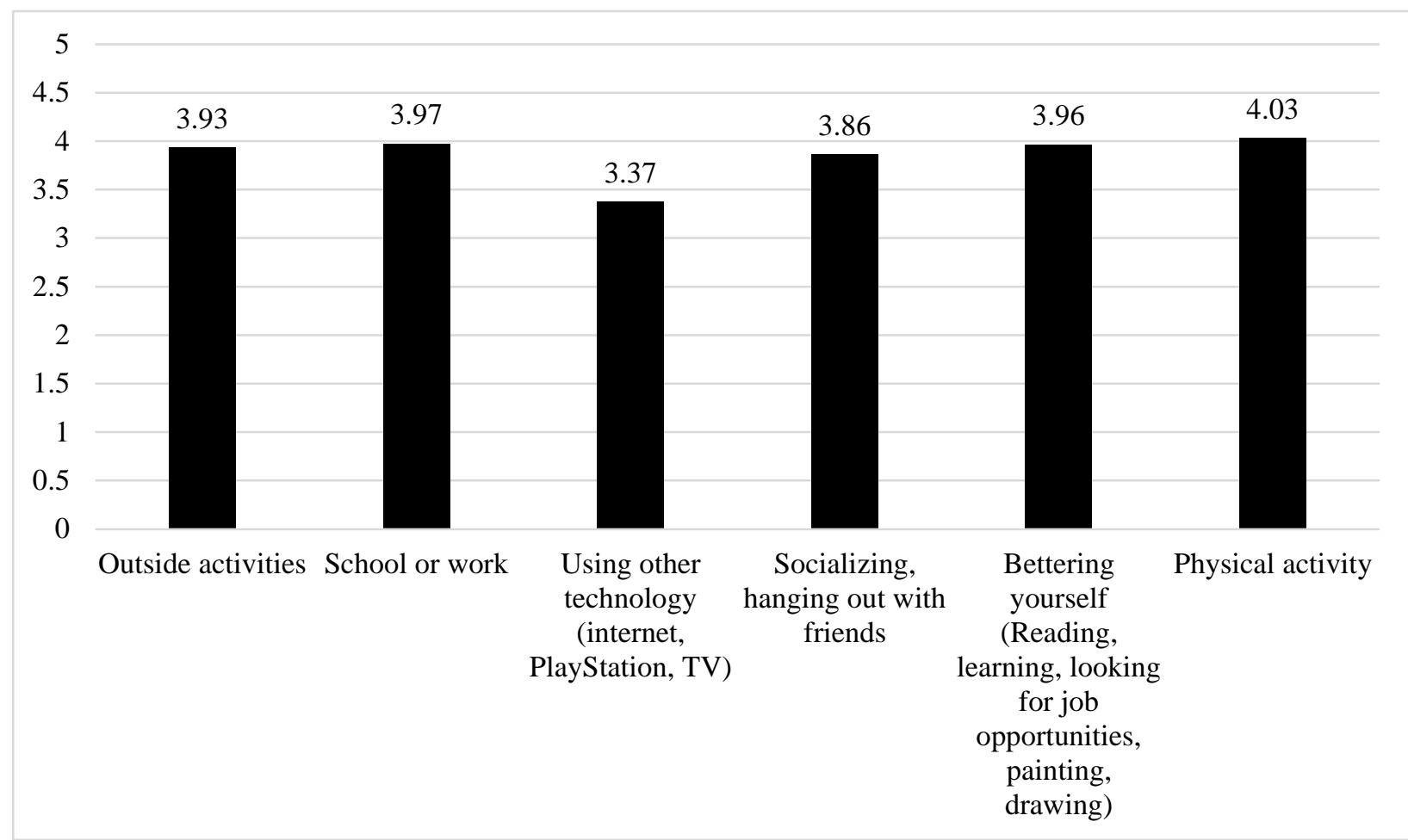

Figure 10. Average response to our item about how likely were the students to engage in an activity in place of engaging with social media

\section{Discussion}

In our research we set out to document students' perceptions, practices, and uses of social media when self-determined in their engagement with the media, deciding what to view, the duration, the frequency, and when and where to view the media. Given that most students' engagement in social media is self-determined we decided that it was important to empirically document their preferences for social media, why they engaged with it, how they used the media, and what activities they might engage in if they were not engaging in social media.

In our examination of how students define social media, we found numerous contradictions. While most of our participants agreed that social media is a media that connects people, most did not perceive texting to be social media even when it met their criteria for the media that connects people. Further, when asked to define social media, very few students could provide a representative comprehensive definition of social media. Our data suggests that while most students engage with social media regularly to frequently, they have a limited perspective of what qualifies as social media or conflicting perceptions of the media. Few students agreed that texting qualified as social media. Our examination of the justifications of those students who did not consider texting to be social media revealed answers that led to contradictions and conflicts with their original perceptions. We speculate that students' perceptions of what qualifies as social media may be highly contextual and malleable, influenced by the setting and nature of the interactions. Further, while they may interact frequently with social media they may not have spent much time thinking about the associated aspects and components that define social media: a blind-spot phenomenon. Because the students typically struggle to define social media they may be more likely to engage in a number of self-determined media interactions without deep consideration of the ramifications and implications for their actions, such as public exposure of confidential information.

Our second guiding research question focused our exploration on the students' views of the perceived impact of social media on individuals and the greater community. Our analysis revealed multiple significant relationships between social media use and potentially detrimental processes or outcomes. For example, we found a significant relationship between social media having a negative impact on personal relationships and checking social media when waking up at night. The relationships suggest that when students engage in self-determined interactions with social media they are likely to also be self-determined in deciding appropriate norms and acceptable outcomes of their interactions. We speculate that the high levels of control and versatility that students have with social media may lead to perceptions that they cannot only choose what to look at, but when, where, and how long. The lack of 
conforming to specific norms may lead to deviant, risky, or antisocial behaviors. Thus, the promotion of certain norms in self-determined social media interactions may be helpful for providing students acceptable guidelines for their associated behaviors.

Our finding that students perceive social media to be a distraction and takes them away from more personal interactions suggests that they are perhaps overly engaged with social media and using the media in ways that are not necessarily balanced with other personal interactions. Again, the self-determined nature of social media interactions may lead to the formation of norms and practices that are not necessarily beneficial or productive. Thus, while self-determined interactions with social media may allow students to engage in conversations and information of their choice, it may also permit them to self-determine their norms and practices that may lead to deviant behaviors and detrimental outcomes.

In our examination of the social media platforms students tended to use, we found a fair amount of consistency among the students. Our data indicated that few students were exploring beyond the common mainstream applications suggesting that in their self-determined social media interactions they are likely to be rather stable in their preferred platform use. In terms of when and where students feel it is acceptable to look at social media, several students responded with perceptions that are likely consistent with societal norms, suggesting that they have used societal practices to guide their interactions. However, responses from a number of students regarding times of unacceptable incidences of engaging with social media reflected behaviors inconsistent with societal norms, suggesting many students may also selectively self-determine norms for social media interactions. The potential issue with developing individual norms for social media interaction is the potential to develop deviant behaviors (e.g. checking media in class, while driving, or while on a date) that may be detrimental or dangerous to others. Thus, helping students learn acceptable norms are based on safety and civility is critical to assuring their adoption of positive social media interaction behaviors.

In our examination of why students engaged with social media, we found that over half indicated it was to connect with others and stay informed, which seems appropriate for social media. However, we also found people using social media to fill time and be entertained, uses that were likely never at the forefront of perceived uses of social media. The use of social media for purposes that are not aligned with social interactions suggests that students are also self-determining how social media should be used.

In terms of the information they are seeking the students indicated that about $30 \%$ of the time they used social media to get status updates. Newsfeeds and other social related activities such as events were included in about $25 \%$ of the responses. These data suggest that students do use social media for social focused purposes, however, our data does not allow us to explain what they are seeking and why they are seeking this information, which would be a potentially fruitful direction for future research.

We began our examination of what students would do if they did not have access to social media by determining if they perceived that they gave up other activities to engage with social media, and if they perceived they would have additional time in their day if social media was nonexistent. Our findings revealed contradictory responses. While students tended to disagree they give up other activities to engage in social media they tended to agree that they would have more time in their day if social media was non-existent. We interpret these results to indicate that students do not want to recognize that they give up activities to engage with social media, but do realize that their engagement with social media is time consuming. Further, these findings are consistent with the students' consideration of social media to be a distraction and time consuming and taking away from personal interactions. The potential for students to ignore the risks and detrimental impact associated with social media use may influence students' determination of acceptable norms and provide justification for a range of potential complications such as Internet addiction and poor academic achievement.

The nearly ubiquitous engagement in inappropriate social media use suggests that it may be very common for students to develop norms for their self-determined use with the recognition that what they are doing is likely to be seen by others as unacceptable. Yet, the students seemed to want to provide justification for their inappropriate behaviors such as being in a boring situation, which suggests a recognition of the potential issue of engaging with social media in inappropriate times and places. We speculate that the lamenting use of social media at inappropriate times indicates that the students are aware of appropriate social norms but may lack the self-regulation to conform to the norms due to habitual social media engagement. Further exploration of inappropriate engagement with social media is an excellent direction for future research,

The students' responses to the list of activities they would engage in if they were not engaging with social media, revealed they were very likely to engage in non-technology activities. They were more likely to exercise, study, and 
work on bettering themselves. The students' responses suggest that these activities may not be considered as readily or may be neglected in place of interacting with social media. Thus, the self-determined nature of social media interaction may be extended to other activities if the students did not have access to social media. Perhaps helping students limit their social media interactions may help them strike a balance in their time management and activity choices.

\section{Implications}

Student engagement in heutagogy using social media may lead to the acquisition of knowledge that may or may not be relevant beyond personal use or entertainment. Further, in their heutagogy processes with social media students may form and apply their own norms, leading to behaviors and practices that may potentially conflict with other students and the greater society. Given that the students are unlikely to be using social media for academic related learning, the information they do receive may reinforce their preference for the information they seek and the support the norms that they use to engage with social media. Given the rather frequent interactions that students have with social media there is a need to help them determine appropriate guidelines for use as well as how to seek information that may be beneficial to their success as students and professionals.

\section{Limitations}

The first limitation of our research was our sample size. Although our sample size was sufficient to determine trends and activities of the students, a larger sample size may provide greater support for our analysis and conclusions. Regardless, the trends were consistent and commensurate with our expectations and our observed behaviors of the students. A future direction for research is to investigate the perceptions, and practices of a larger sample of students.

Our second limitation was the location from which our sample was drawn. All participants were from the same university. It is possible that a great diversity of students would lead to different conclusions; however, the trends we exposed in our data were consistent with the literature. A potential interesting direction for future research is to investigate the social media perception and practices of a diversity of student populations from a variety of locations.

The third major limitation of our research was the nature of our data collection, which was a combination of qualitative and quantitative data, were collected using a survey. The use of a survey did not allow us to follow-up on the response to the student. Thus, we were not able to determine why the participants answered as they did and to gain clarifications of their responses. Regardless, we found a high level of consistency of the participants' responses, suggesting that they responded to our survey in an authentic and honest manner. However, future research may involve more interviews that gain clarification of student perspectives to determine if our research was truly reflective of students' perceptions and practices with social media.

\section{Conclusion}

As social media continues to develop as an integral part of our society we need to consider how interaction with the media is impacting students. Given the potential influence of social media and the self-determined nature of social media interaction, students are likely to be immersed in a condition of heutagogy that extends beyond choice of information to consider to include behaviors. We found students are also choosing the norms and practices that they engage in, which included behaviors that are potentially detrimental to themselves and others. While students may recognize these situations, they may lack the self-regulation to control themselves to not engage in potentially unhealthy situations. Further, engagement in social media may be at the expense of healthier and fulfilling activities. Knowing these conditions exist is critical to raising students' awareness of healthy social media engagement and helping them consider the ramifications of their actions, find moderation in their use, and seek opportunities to engage in alternative activities.

\section{References}

Achen, R. M. (2015). Using Facebook and Twitter to encourage physical activity: Are college students connecting with campus recreation on social media? A pilot study. Recreational Sports Journal, 39(2), 132-143. https://doi.org/10.1123/rsj.2014-0046

Blaschke, L. M. (2012). Heutagogy and lifelong learning: A review of heutagogical practice and self-determined learning. The International Review of Research in Open and Distributed Learning, 13(1), 56-71. https://doi.org/10.19173/irrodl.v13i1.1076

Blaschke, L. M. (2014). Using social media to engage and develop the online learner in self-determined learning. Research in Learning Technology, 22. https://doi.org/10.3402/rlt.v22.21635

Bolton, R. N., Parasuraman, A., Hoefnagels, A., Migchels, N., Kabadayi, S., Gruber, T., ... \& Solnet, D. (2013). 
Understanding Generation Y and their use of social media: a review and research agenda. Journal of Service Management, 24(3), 245-267. https://doi.org/10.1108/09564231311326987

Burak, L. (2012). Multitasking in the university classroom. International Journal for the Scholarship of Teaching and Learning, 6(2), 8. https://doi.org/10.20429/ijsotl.2012.060208

Centola, D. (2013). Social media and the science of health behavior. Circulation, 127(21), 2135-2144. https://doi.org/10.1161/CIRCULATIONAHA.112.101816

Chen, B., \& Bryer, T. (2012). Investigating instructional strategies for using social media in formal and informal learning. The International Review of Research in Open and Distributed Learning, 13(1), 87-104. https://doi.org/10.19173/irrodl.v13i1.1027

Cheung, C. M., Chiu, P. Y., \& Lee, M. K. (2011). Online social networks: Why do students use facebook? Computers in Human Behavior, 27(4), 1337-1343. https://doi.org/10.1016/j.chb.2010.07.028

Correa, T., Hinsley, A. W., \& De Zuniga, H. G. (2010). Who interacts on the Web?: The intersection of users' personality and social media use. Computers in Human Behavior, 26(2), 247-253. https://doi.org/10.1016/j.chb.2009.09.003

Dabbagh, N. \& Kitsantas, A. (2012). Personal Learning Environments, social media, and self-regulated learning: A natural formula for connecting formal and informal learning. The Internet and Higher Education, 15(1), 3-8. https://doi.org/10.1016/j.iheduc.2011.06.002

Deci, E. L., \& Ryan, R. M. (2000). The" what" and" why" of goal pursuits: Human needs and the self-determination of behavior. Psychological inquiry, 11(4), 227-268. https://doi.org/10.1207/S15327965PLI1104_01

Ellison, N. B., Steinfield, C., \& Lampe, C. (2007). The benefits of Facebook "friends:" Social capital and college students' use of online social network sites. Journal of Computer - Mediated Communication, 12(4), 1143-1168. https://doi.org/10.1111/j.1083-6101.2007.00367.x

Gikas, J., \& Grant, M. M. (2013). Mobile computing devices in higher education: Student perspectives on learning with cellphones, smartphones \& social media. The Internet and Higher Education, 19, 18-26. https://doi.org/10.1016/j.iheduc.2013.06.002

Gray, R., Vitak, J., Easton, E. W., \& Ellison, N. B. (2013). Examining social adjustment to college in the age of social media: Factors influencing successful transitions and persistence. Computers \& Education, 67, 193-207. https://doi.org/10.1016/j.compedu.2013.02.021

Grosseck, G., Bran, R., \& Tiru, L. (2011). Dear teacher, what should I write on my wall? A case study on academic uses of Facebook. Procedia-Social and Behavioral Sciences, 15, 1425-1430. https://doi.org/10.1016/j.sbspro.2011.03.306

Hase, S., \& Kenyon, C. (2000). From andragogy to heutagogy. Ultibase Articles, 5(3), 1-10.

Isaacs, D. (2014). Social media and communication. Journal of Paediatrics and Child Health, 50(6), 421-422. https://doi.org/10.1111/jpc. 12555

Jacobsen, W. C., \& Forste, R. (2011). The wired generation: Academic and social outcomes of electronic media use among university students. Cyberpsychology, Behavior, and Social Networking, 14(5), 275-280. https://doi.org/10.1089/cyber.2010.0135

Junco, R. (2012). The relationship between frequency of Facebook use, participation in Facebook activities, and student engagement. Computers \& Education, 58(1), 162-171. https://doi.org/10.1016/j.compedu.2011.08.004

Junco, R. (2015). Student class standing, Facebook use, and academic performance. Journal of Applied Developmental Psychology, 36, 18-29. https://doi.org/10.1016/j.appdev.2014.11.001

Kandell, J. J. (1998). Internet addiction on campus: The vulnerability of college students. CyberPsychology \& Behavior, 1(1), 11-17. https://doi.org/10.1089/cpb.1998.1.11

Karpinski, A. C., Kirschner, P. A., Ozer, I., Mellott, J. A., \& Ochwo, P. (2013). An exploration of social networking site use, multitasking, and academic performance among United States and European university students. Computers in Human Behavior, 29(3), 1182-1192. https://doi.org/10.1016/j.chb.2012.10.011

Kittinger, R., Correia, C. J., \& Irons, J. G. (2012). Relationship between Facebook use and problematic Internet use among college students. Cyberpsychology, Behavior, and Social Networking, 15(6), 324-327. https://doi.org/10.1089/cyber.2010.0410 
Korda, H., \& Itani, Z. (2013). Harnessing social media for health promotion and behavior change. Health Promotion Practice, 14(1), 15-23. https://doi.org/10.1177/1524839911405850

Mcandrew, F. T., \& Jeong, H. S. (2012). Who does what on Facebook? Age, sex, and relationship status as predictors of Facebook use. Computers in Human Behavior, 28(6), 2359-2365. https://doi.org/10.1016/j.chb.2012.07.007

Nadelson, L. S., Sias, C. M., Matyi, J., Morris, S. R., Cain, R., Cromwell, M., ... \& Seegmiller, J. (2016). A world of information at their fingertips: college students' motivations and practices in their self-determined information seeking. International Journal of Higher Education, 5(1), 220. https://doi.org/10.5430/ijhe.v5n1p220

Pempek, T. A., Yermolayeva, Y. A., \& Calvert, S. L. (2009). College students' social networking experiences on Facebook. Journal of Applied Developmental Psychology, 30(3), 227-238. https://doi.org/10.1016/j.appdev.2008.12.010

Petrocchi, N., Asnaani, A., Martinez, A. P., Nadkarni, A., \& Hofmann, S. G. (2015). Differences between people who use only facebook and those who use facebook plus twitter. International Journal of Human-computer Interaction, 31(2), 157-165. https://doi.org/10.1080/10447318.2014.986640

Quan-Haase, A., \& Young, A. L. (2010). Uses and gratifications of social media: A comparison of Facebook and instant messaging. Bulletin of Science, Technology \& Society, 30(5), 350-361. https://doi.org/10.1177/0270467610380009

Roberts, D. F., Foehr, U. G., \& Rideout, V. J. (2005). Generation M: Media in the lives of $8-18$-year-olds. Menlo Park, CA: Kaiser Family Foundation. Retrieved from http://www.kff.org/entmedia/upload/ 8010.pdf

Ryan, R. M., \& Deci, E. L. (2000). Self-determination theory and the facilitation of intrinsic motivation, social development, and well-being. American psychologist, 55(1), 68. https://doi.org/10.1037/0003-066X.55.1.68

Sánchez, R. A., Cortijo, V., \& Javed, U. (2014). Students' perceptions of Facebook for academic purposes. Computers \& Education, 70, 138-149. https://doi.org/10.1016/j.compedu.2013.08.012

Tandoc, E. C., Ferrucci, P., \& Duffy, M. (2015). Facebook use, envy, and depression among college students: Is facebooking depressing? Computers in Human Behavior, 43, 139-146. https://doi.org/10.1016/j.chb.2014.10.053

Tess, P. A. (2013). The role of social media in higher education classes (real and virtual)-A literature review. Computers in Human Behavior, 29(5), A60-A68. https://doi.org/10.1016/j.chb.2012.12.032

Valenzuela, S., Park, N., \& Kee, K. F. (2009). Is there social capital in a social network site? Facebook use and college students' life satisfaction, trust, and participation. Journal of Computer-Mediated Communication, 14(4), 875-901. https://doi.org/10.1111/j.1083-6101.2009.01474.x

Vishwanath, A. (2015). Habitual Facebook use and its impact on getting deceived on social media. Journal of Computer - Mediated Communication, 20(1), 83-98. https://doi.org/10.1111/jcc4.12100

Wegmann, E., Stodt, B., \& Brand, M. (2015). Addictive use of social networking sites can be explained by the interaction of Internet use expectancies, Internet literacy, and psychopathological symptoms. Journal of behavioral addictions, 4(3), 155-162. https://doi.org/10.1556/2006.4.2015.021 